\title{
Jorge Graciarena, na Perspectiva Latino-Americana: notas in memoriam ${ }^{1}$
}

Recebido: 06-09-2017

Aprovado: 21-10-2018

Waldo Ansaldi ${ }^{2}$

Verónica Giordano ${ }^{3}$

\section{Introdução}

Em março de 2014 faleceu Jorge Gracirena, que foi uma das figuras fundacionais da sociologia argentina e latino-americana. No entanto, as referências à sua vasta produção aparecem tão somente de forma esporádica nos programas dos cursos de sociologia hoje em dia.

Não é o único. Este destino é compartilhado por outros intelectuais que como ele contribuíram de forma muito criativa para a consolidação de nossas ciências sociais. Tal é o caso de Sergio Bagú, outro argentino radicado no México, e de Orlando Fals Borda, fundador da sociologia junto a Camilo Torres em 1959 na Colombia. Também é o caso do colombiano Antonio Garci e sua sociologia da reforma agrária na América Latina, publicado em 1973, para citar apenas alguns dos grandes ausentes. Seguramente, sobre estas circunstâncias pesa o legado do colonialismo intelectual que, nos anos noventa, recrudesceu com a presença do neoliberalismo em voga, invisibilizando o pensamento próprio.

Homem longevo, nasceu em 1922 e faleceu em 2014, Graciarena transitou os últimos 25 anos de sua vida praticamente fora dos foros acadêmicos. Em 1986, recebeu o Diploma ao Mérito na categoria de Sociologia, outorgado pelos Prêmios Konex (Buenos Aires, Argentina). A nota biográfica publicada em dita ocasião é uma das poucas que se conhecem de Graciarena. Esta nota explicita:

\footnotetext{
${ }^{1}$ Texto traduzido do idioma original (espanhol) por Emanuela Gava Caciatori e Lucas Machado Fagundes, membros do grupo de pesquisa: "Pensamento Jurídico Crítico Latino-americano" da Universidade do Extremo Sul Catarinense - UNESC

${ }^{2}$ Professor Titular do Curso de Sociología, na Facultad de Ciencias Sociales na Universidad de Buenos Aires UBA. Doutor em História pela Universidade Nacional de Córdoba. Contato: waldoansaldi@gmail.com

${ }^{3}$ Professora Adjunta de Sociología Histórica de América Latina do Curso de Sociología, na Facultad de Ciencias Sociales na Universidad de Buenos Aires - UBA. Doutora em Ciências Sociais pela Universidad de Buenos Aires - UBA. Contato: veronicaxgiordano@gmail.com
} 
Doutor em Ciências Econômicas e Sociológicas. Realizou estudos pós-doutorais na London School of Economics em Londres (Inglaterra). Formou parte do grupo que fundou em 1957 o curso de Sociologia da Universidade de Buenos Aires junto à Gino Germani e José Luis Romero. Particularmente, foi o redator do programa de estudos. Em 1966 trabalhou como funcionário da UNESC em Bogotá, Montevidéu e Rio de Janeiro. Logo, integrou a divisão de Desenvolvimento Social da Comissão Econômica para América Latina (CEPAL) em Santiago no Chile, no marco do Programa das Nações Unidas para o Desenvolvimento. Publicou importantes obras acadêmicas de economia e sociologia, entre as quais se destacam, Antologia: da sociedade tradicional à sociedade das massas, com Gino Germani (1964), Poder e classes sociais no desenvolvimento da América Latina (1967), Entre realidade e utopia: a dialética das ciências sociais latino-americanas (1978) e Estudos de pós-graduação em Ciências Sociais $(1982)^{4}$.

Desta curta informação surge imediatamente a notável atuação que Graciarena teve no campo das Ciências Sociais na América Latina no transcurso das largas décadas. Nestas breves notas abordamos três aspectos: a originalidade do seu pensamento, para além da sociologia "científica"; sua preocupação pelos estudos de pós-graduação como prisma a partir do qual captar essa originalidade em ato; a atenção posta na dimensão histórica da realidade. Este último, a modo apresentação do texto "O Estado latino-americano em perspectiva. Figuras, crises e prospectivas”, publicado originalmente em Madrid em 1984.

\section{Para Além da Sociologia "Científica"}

Na América Latina, a sociologia leva a marca indelével da interdisciplinaridade, ou mesmo da hibridação das disciplinas (Giordano, 2014). Os diálogos e trânsitos entre fronteiras disciplinárias são evidentes nos primeiros passos em direção a institucionalização da sociologia como ciência. Pensemos em Gino Germani (1911-1979) e sua graduação em economia e filosofia; em Pablo González Casanova (1922-) e suas primeiras incursões na história e na antropologia; em Orlando Fals Borda (1925-2008) e seus estudos em literatura inglesa; em Edelberto Torres Rivas (1932-) e seu título de advogado. Ou inclusive em Sergio Bagú (1911-2002) e sua multidisciplinaridade, mesmo sem título universitário algum.

$\mathrm{Na}$ Argentina, a institucionalização da sociologia como ciência foi associada primordialmente à figura de Gino Germani, sem dúvida o pai fundador. Mas Germani não esteve só nesta empreitada, foi antes de tudo uma figura aglutinadora de um conjunto heterogêneo de jovens intelectuais, entre os quais destacou-se Jorge Graciarena, por sua inteligência aguda.

Graciarena formou-se como contador público nacional na Faculdade de Ciências Econômicas da Universidade de Buenos Aires (UBA) e obteve o título de Doutor em Economia na mesma instituição. Nos anos do peronismo, uniu-se à militância universitária e

\footnotetext{
${ }^{4}$ Fundación Konex. Véase www.fundacionkonex.org/b1075-jorge-graciarena.
} 
política no campo da esquerda, vinculando-se com quem mais tarde também seriam reconhecidos sociólogos: Juan Carlos Marín e Miguel Murmis.

Graciarena formou parte do círculo de jovens que rodeou a José Luis Romero (19091977), reunindo-se periodicamente na casa que este tinha em Adrogué. Haviam se conhecido nos cursos paralelos que ditavam na Faculdade de Ciências Econômicas da UBA e no Colégio Livre de Estudos Superiores (ACHA, 2005, p. 38), duas experiências que tem centralidade no contexto das mudanças levadas adiante pelo peronismo na universidade, que implicaram inclusões para uns e exclusões para outros. Assim, Graciarena se vinculou com Romero, mas também com Gino Germani, quem logo seria seu mentor.

Em 1955, ano do golpe que depôs Juan D. Perón, Romero foi nomeado reitor interventor da UBA e Graciarena foi seu secretário. Junto a Marín, Murmis e outros, participava então das reuniões da Juventude Socialista que se aglutinava em torno da figura de Romero (ACHA, 2005, p. 39). Ademais, Graciarena, trabalhava de contador na Imago Mundi, Revista de História da Cultura, um projeto intelectual que teve início em 1953 e foi concluído três anos depois. Até então Romero já havia deixado o cargo de reitor da universidade. Tal como sustenta Acha (2005, p. 67), Imago Mundi foi um projeto encabeçado por Romero, que convocou a um conjunto heterogêneo de pessoas e perspectivas, em sua maioria inscritas no que poderia denominar-se um "humanismo secularizado". Este mesmo autor afirma que foi um empreendimento cultural que não se imiscuiu na antinômica política nacional de modo direto, mas indiretamente, e, utilizando os objetos culturais como veículo, fixou sua posição opositora ao peronismo.

A partir do golpe de 1955, o grupo reunido em torno à figura de Romero passou a encabeçar a renovação acadêmica. Isso implicou o fortalecimento do cientificismo. Neste marco, em março de 1957, o Conselho Superior da UBA criou a graduação em Sociologia no seio da Faculdade de Filosofia e Letras. Encabeçado por Germani, Graciarena formou parte do grupo fundacional. Foi o redator do programa de estudos ${ }^{5}$. Coincidia com Germani nas perspectivas teóricas sobre a internacionalização dos modelos de ciência (Blanco, 2005).

Desta fase de gestação da sociologia acadêmica, surgiu um texto emblemático que publicaram Germani, Graciarena e Torcuato Di Tella - outro dos jovens destacados que participaram da institucionalização da sociologia no país -; Argentina, sociedade de massas.

\footnotetext{
${ }^{5}$ Fundación Konex. Véase www.fundacionkonex.org/b1075-jorge-graciarena.
} 
O livro compilava algumas das intervenções dos participantes nas Jornadas argentinas e Latino-amaericanas de Sociologia realizadas em Buenos Aires em $1961^{6}$.

Na ocasião, Graciarena apresentou "Desenvolvimento e política". Nesse mesmo ano, também produziu "Duas alternativas políticas ao desenvolvimento: mudança gradual ou revolução", no qual já despontava o sociólogo comprometido em indagar sobre os grandes tópicos da sociologia histórica, neste caso em grande escala ${ }^{7}$.

A mudança de perspectiva que se perfilava nestes textos cobrou maior entidade em seu livro Poder e classes sociais no desenvolvimento da América Latina de 1967. Trata-se de um livro no qual reúne alguns trabalhos inéditos e outros já publicados (entre 1961-1966), mas reelaborados a partir das novas ideias que havia coletado na sua passagem pela London School of Economics e sua participação em distinto foros latino-americanos.

Assim, o livro contém dois trabalhos chaves para entender o giro em suas perspectivas de análise. No capítulo II, "Da oligarquia à elite do poder: uma transição incompleta", Graciarena desqualifica as tipologias dicotômicas, em particular aquelas que opõe o conceito de oligarquia ao conceito de elite, e consequentemente o conceito de sociedade agrária ao de sociedade industrial, ou dito de outro modo, o tradicional e o moderno. O capítulo IV é outro dos textos destacados. Nele, Graciarena brinda uma ferramenta metodológica muito própria do seu tempo: não atender exclusivamente à dimensão econômica da dependência mas também à política e social, em seu caso em uma reflexão sobre o fenômeno da integração regional. Daqui o título do capítulo: "Uma perspectiva política da integração latinoamericana".

O período em que Graciarena concebeu os textos reunidos em Poder e classes sociais [...], esteve atravessado por mudanças precipitadas na Argentina. Muitos dos jovens que Germani havia estimulado a formar-se no exterior regressaram ao país e se inseriram em cheio no clima político universitário e nacional, distanciando-se do seu "mestre" e afirmando suas convicções marxistas contra o estrutural funcionalismo (Ansaldi, 1992, p. 69-70). Diferenças políticas, ideológicas e teóricas levaram a Germani a renunciar o cargo de diretor do Departamento de Sociologia; após várias viagens aos Estados Unidos, finalmente em 1965 foi designado professor em Harvard.

\footnotetext{
${ }^{6}$ Evento realizado en el marco de la conmemoración del Sesquiscentenario de la Revolución de Mayo en Buenos Aires, los días 25 a 29 de septiembre de 1961. Ver: Sánchez Crespo, Alberto, «Jornadas Argentinas y Latinoamericanas de Sociología», Desarrollo Eco- nómico, Vol. 1, No 3, octubre-diciembre, 1961, pp. $229-242$.

${ }^{7}$ Publicado en Revista de la Universidad de Buenos Aires, 5ta época, tomo 6, pp. 5-18.
} 
Em outro texto foi assinalado (Ansaldi, 1991, p. 43-44) que esse mesmo período foi o momento da latino americanização do corpo de docente da FLACSO, onde professores latinoamericanos ocuparam espaços centrais, enquanto professores europeus contratados pela UNESCO perderam peso relativo dentro da Faculdade (como o suíço Peter Heintz ou o norueguês Johan Galtung, entre outros). Poderia dizer-se que neste período também Graciarena experimentou a latinoamericanização de suas perspectivas teóricas e metodológica, ademais de uma aproximação mais evidente à "sociologia do conflito".

Estas perspectivas e problemas foram a marca original da sua produção nos anos sucessivos. O último de seus mais acabados trabalhos nesta linha de pensamento foi "O Estado latino-americano em perspectiva", de 1984. Neste texto coincide com o fechamento da uma etapa na trajetória de Graciarena. De regresso na Argentina, terá uma breve passagem pela Secretaria de Repatriação do governo de Raúl Alfonsín (1983-1989), para logo retirar-se quase definitivamente da vida pública.

Alguns marcos ajudam a delinear a destacada trajetória traçada até aqui. Em 1964, Graciarena havia participado do VII Congresso Latinoamericano de Sociologia, realizado em Bogotá entre 15 e 19 de julho, no qual estimulou o pensamento próprio sobre os problemas da região (FALS BORDA, 1970, p. 50). Sob o título, “A sociologia e a transformação atual da América Latina", convocava a refletir sobre a mudança social.

Na convocatória se admitia: "É certo que o tema da sociologia do desenvolvimento foi saturada nos últimos congressos mundiais de sociologia e disciplinas afins”. E imediatamente se alentava: "demonstrava que se deu um passo a mais em direção à maturidade conceitual"8.

A partir dos foros como este Congresso celebrado em Bogotá, Graciarena elaborou um tipo de sociologia que se distanciava da sociologia "científica" de Germani para emparentarse melhor com este outro tipo que identificou como "sociologia do conflito". Segundo explica o próprio Graciarena no apêndice I do seu livro Poder e classes sociais [...], "cada uma delas [os tipos de sociologia] significa uma distinta seleção de problemas e um ocultamento de outros" (Graciarena, 1967, p. 261). Com o título "Notas sobre orientações da teoria sociológica e tipos de problemas", este apêndice não é somente uma lição de sociologia, mas também um testemunho da virada de Graciarena para uma sociologia preocupada pelos grande problemas da sociologia histórica.

\footnotetext{
${ }^{8}$ Revista Estudios de Derecho, Segunda época, Vol. XXII, núm. 64, p. 287.
} 


\section{A Preocupação pelos Estudos de Pós-Graduação}

Em 1958, FLACSO organizou o Seminário Latino-americano sobre Metodologia do Ensino e pesquisa das Ciências Sociais, em Santiago no Chile entre 22 e 28 de setembro. Em representação argentina, viajaram Germani e Graciarena (BLANCO, 2005) ${ }^{9}$. Em texto conjunto, apresentaram o informe intitulado "Ensino e pesquisa da Sociologia, Ciência Política e Economia, A situação na Argentina" (DAMIANO, 2009) 10.

Este trabalho reflete a vocação da sociologia argentina naquele momento: a vinculação entre ensino e pesquisa, um aspecto do qual Graciarena ocupou-se especialmente ao largo da sua carreira e que hoje ainda alimenta as perspectivas de revitalizar a formação própria (latino-americana e latinoamericanista) em ciências sociais. Neste campo, suas contribuições foram especialmente valiosas. Cabe então recordar brevemente a respeito.

Os cientistas sociais latino-americanos estiveram em um âmbito formidável para o intercâmbio de ideias na FLACSO. Com sede em Santiago no Chile, esta instituição abrigou a Escola Latino-americana de Sociologia (ELAS) e a Escola Latino-americana de Ciência Política e Administração Pública (ELACP), experiências levadas adiante a partir de 1957, a primeira, e de 1966, a segunda. Outro âmbito predileto foi a CLACSO, que entre 1970 e 1973 levou adiante o projeto do programa de Pós-graduação em Ciências Sociais. Dois importantes centros de estudos quaternários foram o Instituto Latino-americano de Planejamento Econômico e Social (ILPES) e o Centro Latino-americano de Demografia (CELADE), ambos parte da CEPAL, criados em 1962 e 1966 e com sede em Santiago e Montevidéu, respectivamente.

A estes centros se deve somar a experiência de alguns congressos científicos significativos realizados na região, como o II Congresso de Sociologia celebrado em Bogotá em 1967, onde Graciarena apresentou "Sociologia e ideologia: alguns problemas na orientação da formação de sociólogos na América Latina"11. Foi neste momento que se esboçou os lineamentos principais que o levariam a interessar-se especialmente no caráter do ensino das ciências sociais na região.

Para boa parte dos cientistas sociais latino-americanos dos anos sessenta, o ensino, a pesquisa e a formação dos recursos humanos requeria, imprescindivelmente, desenvolver a

\footnotetext{
${ }^{9}$ Participaron figuras fundantes de la sociología latinoamericana como José Medina Echavarría (FLACSO), Orlando M. Carvalho y Luiz A. Costa Pinto de Brasil y Pablo González Casanova de México, entre tantos otros.

${ }^{10}$ Publicado en el Boletín del Instituto de Sociología.

${ }^{11}$ Publicado bajo ese mismo título en Revista Mexicana de Sociología, Vol. 30, núm. 4, octubre-diciembre, 1968, pp. 795-818.
} 
capacidade de juízo autônomo, como modo de aliviar o peso do juízo dos outros, ou seja, dos extra-regionais. Buscava-se nacionalizar/regionalizar, em localização espacial e em conteúdos, a formação de pós-graduação. A tendência a nacionalização não foi entendida, em geral, como ruptura com os centros científicos extra-regionais. Assim sendo, se postulava intensificar os vínculos com estes, "mas fazendo-os mais maduros e 'adultos' que na atualidade [...], a partir de uma posição mais autônoma, com maior capacidade de detectar $e$ selecionar as alternativas mais convenientes aos interesses nacionais" (GRACIARENA, 1974, p. 42, grifo dos autores).

Para Graciarena (1974, p. 40-41), entre outros, a "nacionalização da formação de pósgraduação" devia realizar-se, em primeiro lugar, nas universidades da região. Entretanto, todos, rapidamente, perceberam nelas fortes limites (institucionais e políticos) para uma tarefa dessa magnitude. A prevenção sobre a real potencialidade universitária para resolver adequadamente o desafio se fundava, em boa parte, na crise das universidades, um ponto sobre o qual havia um generalizado consenso. As universidades latino-americanas foram percebidas, em sua maioria, como anacrônicas e resistentes à mudança, ao que se agregava dado não menos importante: a tendência dos vários governos ditatoriais ou meramente autoritários cercear ou limitar fortemente a autonomia financeira e acadêmica das universidades.

Foi nesse contexto que surgiu a iniciativa da CLACSO na qual Graciarena desempenhou uma destacada atividade. O projeto tinha como objetivo prioritário o reforço do treinamento avançado dentro da própria América Latina. O ponto de partida foi fazer frente aos problemas de tal objetivo atendendo aos cursos de mestrado existentes e a criação de cursos de doutorado de alto nível, concentrando os recursos disponíveis em várias cidades da América Latina e regionalizando a participação e os benefícios do programa. As cidade bases escolhidas, em função do nível acadêmico dos seus cursos e da disponibilidade de recursos humanos, foram Rio de Janeiro, São Paulo, Buenos Aires, México DF e Santiago no Chile. Uma formidável tarefa de revelação e de análises de possíveis vias para efetivar-se o projeto foi realizada por cinco grupos de trabalho que reuniu 48 cientistas sociais da Argentina, Brasil, Chile, Colômbia, México, Paraguai e Peru. Os resultados dos primeiros anos de trabalho foram expostos na "Bases para um Programa Latino-americano de Estudos de Pósgraduação em Ciências Sociais", editado pela Secretaria Executiva do Conselho em Buenos Aires, em 1973 (03 tomos), daí derivou o trabalho de Graciarena (1974).

Alguns anos mais tarde, em um seminário realizados em Caracas, em dezembro de 1980, Graciarena, então diretor da Divisão de Desenvolvimento Social da CEPAL, retomava 
uma premissa de José Medina Echavarría: a necessidade de pensar a inserção orgânica das universidades na ordem social vigente, "conexão fundamental" cuja a chave se encontra "na peculiar relação" entre elas ("poder espiritual”) e o Estado (poder político). Ou seja, analisar "como a universidade se relaciona com a estrutura do poder e a dinâmica das classes sociais e, em particular, com a formação de um sistema hegemônico, isto é, de um regime político ideologicamente consensual que dispõe de uma margem ampla de legitimidade social". E acrescia: "A questão que aqui se intenta esboçar é histórica, já que a inserção estrutural da ordem universitária variou com o tempo, mais que tudo devido às transformações das relações de classe e de poder na sociedade" (GRACIARENA, 1980, p. 12-13, grifo dos autores).

A questão posta em debate era a da universidade como formadora de elites do poder, questão que também deveria ser analisada em perspectiva histórica. Encurta-se: Graciarena entendia o conceito de elite do poder no sentido de Charles Wright Mills, pronunciando-se em discrepância com Mosca e Pareto.

Este texto conclui com quatro perguntas, das quais será resumida em uma: "Quanto pluralismo ideológico na universidade de massa pode tolerar uma ordem social elitista com perfis autoritários e tecnocráticos?”. Formulado em um ano no qual as ditaduras institucionais das forças armadas primavam na América Latina, o interrogante centrava-se na articulação entre universidade, Estado e sociedade. Para Graciarena, a resposta era inseparável da busca de uma saída autêntica que, para sê-la, deveria "por força conter um futuro de esperança". A saída lhe parecia possível, fazendo-a "dependente do imaginação criadora e da crítica da razão sobre si mesma, que são propriedades essenciais da inteligência” (1980, p. 28).

\section{A Preocupação pela História: palavras finais ou uma nova introdução}

Para terminar de apresentar Jorge Graciarena e introduzir o leitor em seu "Estado latino-americano em perspectiva" (GRACIARENA, 1984), permita-se agregar algumas linhas mais sobre seu conceito da história.

Encontramos na obra de Graciarena (como na de muitos outros contemporâneos) preocupações sobre questões centrais das sociedades latino-americanas. A análise toma conceitos e categorias típicos da sociologia - hoje relegados - como Estado, classes sociais, poder, mudança social, entre outros, mas utilizados com perspectiva histórica. De fato, em vários dos seus trabalhos, Graciarena insistiu em denominar mudança social como "mudança histórica". 
Entendia por mudança história “as transformações irreversíveis da estrutura do poder e suas fontes principais de legitimação ideológica", para distinguir esta forma de mudança de outras "que podem ser irrelevantes nesse sentido" (GRACIARENA, 1980, p. 10).

Com esta perspectiva de sociologia histórica foi que Graciarena abordou o tratamento da questão da universidade, a formação de profissionais e elites de poder. Também foi com esta categoria que Graciarena produziu o texto que aqui é apresentado.

Graciarena já havia se ocupado do Estado na América Latina em seus escritos sobre o desenvolvimento. Em "Poder e estilos de desenvolvimento, uma perspectiva heterodoxa", destacava o papel do Estado no estabelecimento e preservação de um estilo de desenvolvimento, e assinalava que qualquer estratégia se produzia no marco "das condições e em meio dos conflitos que constituem suas possibilidades histórico-estruturais”. E em uma nota de pé, acrescenta: "O curso do futuro, longe de encontrar-se pré-fixado, está aberto e pode mover-se em várias direções difíceis de prever, mas dentro de certos limites históricos que marcam o que é circunstancialmente possível" (GRACIARENA, 1976, p. 189-190, grifo dos autores). A importância do Estado nas políticas de desenvolvimento - que ele distinguiu em dois momentos sucessivos, qualitativamente diferenciados: a modernização desenvolvimentista sob a ordem democrática e o desenvolvimentismo em um marco autoritário - foi especialmente destacada na seção de sua autoria no livro compartido com Rolando Franco (GRACIARENA; FRANCO, 1981).

Em seu trabalho sobre o Estado na América Latina, que aqui se reproduz, sustenta: "Caso pretenda-se avançar em algum grau de entendimento do que pode ser uma crise do Estado, a dimensão histórica constitui uma perspectiva indissociável” (GRACIARENA, 1948, p. 10).

Na mesma trilha transitava quando propunha analisar a democracia na América Latina (GRACIARENA, 1985, p. 192): "há três elementos que deveriam estar integrados em qualquer interpretação que pretenda ser abarcadora do que significa o fenômeno democrático. Estes são a dimensão social, [a] política [e a] histórica da democracia, cujas conexões recíprocas são as que lhe dão sua densidade e sentido concreto. A conjunção destas dimensões é o que permite observar o grau em que a democracia constitui uma formação histórica que penetrou na sociedade (classes sociais) e no Estado (regime político)”.

Graciarena foi um grande analista das conjunturas do seu tempo. Lhe interessava as conjunturas, sim, mas sempre as leu como processo de larga duração, passado - presente futuro. 


\section{Bibliografia}

ACHA, Omar. La trama profunda. Historia y vida en José Luis Romero. El cielo por asalto: Buenos Aires, 2005.

ANSALDI, Waldo (con la colaboración de Fernando Calderón). La búsqueda de América Latina: entre el ansia de encontrarla y el temor de no reconocerla: teorías e instituciones en la construcción de las ciencias sociales latinoamericanas. Cuadernos núm. 1, Instituto de Investigaciones de la Facultad de Ciencias Sociales: Buenos Aires, 1991.

ANSALDI, Waldo. De historia y de sociología: la metáfora de la tortilla. In: JORRAT, Jorge; SAUTU, Ruth (comps.). Después de Germani: exploraciones sobre estructura social en la Argentina. Paidós: Buenos Aires, 1992.

BLANCO, Alejandro. La Asociación Latinoamericana de Sociología: una historia de sus primeros congresos. Sociologías, núm. 14, diciembre, Porto Alegre, 2005.

DAMIANO, Franco. Enseñando a investigar: Gino Germani y la sociología científica. Trabajo y Sociedad, núm. 13, diciembre, Santiado del Estero, 2009.

GIORDANO, Verónica. La sociología histórica y la sociología latinoamericana. La comparación en nuestras ciencias sociales. Revista de la Red Intercátedras de Historia de América Latina Contemporánea (segunda época), núm. 1, 2014.

GRACIARENA, Jorge. Poder y clases sociales en el desarrollo de América Latina. Paidós: Buenos Aires, 1967.

Formación de postgrado en ciencias sociales en América Latina. Buenos Aires: Paidós, 1974.

Poder y estilos de desarrollo, una perspectiva heterodoxa. Revista de la CEPAL, Primer Semestre, Santiago de Chile, pp. 173-193, 1976.

Universidad, inteligencia e ideología. En torno a algunas ideas de José Medina Echavarría. GRACIARENA, Jorge et al. Universidad y desarrollo en América Latina y el Caribe. CRESALC-UNESCO, pp. 9-28, 1980.

El Estado latinoamericano en perspectiva. Figuras, crisis y prospectiva. Pensamiento Iberoamericano. Revista de Economía Política, núm. 5, Madrid, pp. 39-74, 1984.

La democracia en la sociedad y la política. Apuntes sobre un caso concreto. AAVV, Los límites de la democracia. CLACSO: Buenos Aires, pp. 191-202, 1985.

; ROLANDO, Franco. Formaciones sociales y estructuras de poder en América

Latina. La primera parte de este libro fue redactada por Graciarena; la segunda y la tercera, por Franco]. Centro de Investigaciones Sociológicas: Madrid, 1981. 


\title{
Jorge Graciarena, na Perspectiva Latino-Americana: notas in memoriam
}

\section{Resumo:}

Em março de 2014 faleceu Jorge Gracirena, que foi uma das figuras fundacionais da sociologia argentina e latino-americana. No entanto, as referências à sua vasta produção aparecem tão somente de forma esporádica nos programas dos cursos de sociologia hoje em dia. Nestas breves notas abordamos três aspectos: a originalidade do seu pensamento, para além da sociologia "científica"; sua preocupação pelos estudos de pós-graduação como prisma a partir do qual captar essa originalidade em ato; a atenção posta na dimensão histórica da realidade. Este último, a modo apresentação do texto "O Estado latino-americano em perspectiva. Figuras, crises e prospectivas”, publicado originalmente em Madrid em 1984.

\section{Jorge Graciarena, en Perspectiva Latinoamericana: notas in memoriam}

\section{Resumen}

En marzo de 2014 falleció Jorge Gracirena, que fue una de las figuras fundacionales de la sociología argentina y latinoamericana. Sin embargo, las referencias a su vasta producción aparecen tan sólo de forma esporádica en los programas de los cursos de sociología hoy en día. En estas breves notas abordamos tres aspectos: la originalidad de su pensamiento, más allá de la sociología "científica"; su preocupación por los estudios de postgrado como prisma a partir del cual captar esa originalidad en acto; la atención puesta en la dimensión histórica de la realidad. Este último, a modo presentación del texto "El Estado latinoamericano en perspectiva. Figuras, crisis y perspectivas", publicado originalmente en Madrid en 1984.

\section{Jorge Graciarena, in Latin American Perspective: notes in memoriam}

\begin{abstract}
In March 2014 Jorge Gracirena died, who was one of the founding figures of Argentine and Latin American sociology. However, the references to its vast production appear only sporadically in the programs of sociology courses nowadays. In these brief notes we address three aspects: the originality of his thought, beyond "scientific" sociology; his concern for postgraduate studies as a prism from which to capture this originality in the act; attention to the historical dimension of reality. The latter, as a presentation of the text "The Latin American State in Perspective. Figures, Crises and Prospects", originally published in Madrid in 1984.
\end{abstract}

